\title{
Psuedo static stability analysis of rock slope using patton's shear criterion
}

\author{
Subhadeep Metya* ${ }^{*}$, Neeraj Chaudhary and Keshav Kumar Sharma
}

\author{
${ }^{*}$ Correspondence: \\ smetya.ce@nitjsr.ac.in \\ Department of Civil \\ Engineering, NIT Jamshedpur, \\ Jharkhand 831014, India
}

\begin{abstract}
A deterministic model for the factor of safety of an idealized rock mass for planar mode of failure is developed adopting Limit Equilibrium Method (LEM) using Patton's shear strength criterion and considering practically occurring conditions such as the effect of tension crack, water filled up in tension crack, horizontal and vertical seismic acceleration, rock bolt stabilizing force and surcharge. In the Pseudo-static analysis horizontal seismic acceleration is taken outward from the slope and vertical seismic acceleration is considered in both the direction i.e. towards the direction of gravity (downward) and opposite to the direction of gravity (upward). An expression of normal stresses as limiting criterion has been derived in order to compare the field normal stresses along the failure surface. A detailed parametric study has been presented to investigate the influence of vertical seismic coefficient for both the direction on the stability of rock slope using developed expression. For high normal stress along the failure plane, it is observed that the factor of safety decreases with increase in the value of vertical seismic coefficient towards the direction of gravity and increases linearly with increase in the value of vertical seismic coefficient against the direction of gravity and the opposite trend has been found for lower normal stress. The vertical seismic coefficient against the direction of gravity has predominant effect on factor of safety of rock slope as the rate of increase/decrease of factor of safety with vertical seismic coefficient is more against the direction of gravity. Hence in determining the critical factor of safety, effect of vertical seismic coefficient against the direction of gravity should be considered.
\end{abstract}

Keywords: Anchored rock slope, Slope stability, Deterministic model, Limit equilibrium method, Planar failure, Patton's shear strength criterion

\section{Introduction}

Rock slopes are natural structure specified by presence of rocks with thin overburden at places, containing geological discontinuities such as bedding, foliation, joint, thrust and other such factors. Rock slope stability analysis has been a topic of immense interest due to the presence of several discontinuities.

Intersection pattern of geological discontinuities with slope face has influence on the specific type of failure in rock slope namely planar, wedge, circular, toppling, and buckling $[4,6,13,16,21,27]$. Sliding of rock mass along a failure plane is referred to block failure or plane failure [28]. Planar failure generally occurs in hard or soft rock

(c) The Author(s) 2021. This article is licensed under a Creative Commons Attribution 4.0 International License, which permits use, sharing, adaptation, distribution and reproduction in any medium or format, as long as you give appropriate credit to the original author(s) and the source, provide a link to the Creative Commons licence, and indicate if changes were made. The images or other third party material in this article are included in the article's Creative Commons licence, unless indicated otherwise in a credit line to the material. If material is not included in the article's Creative Commons licence and your intended use is not permitted by statutory regulation or exceeds the permitted use, you will need to obtain permission directly from the copyright holder. To view a copy of this licence, visit http://creativeco mmons.org/licenses/by/4.0/. 
slopes with well-defined discontinuities and joints e.g., layered sedimentary rock, volcanic flow rock, block jointed granite and foliated metamorphic rock [3]. Planar failure also occurs when structural sliding plane dips towards the slope face with dip angle lower angle than that of slope face and higher angle than friction angle of the discontinuity surface $[3,14,27]$.

Over the years, the stability analyses of rock slopes, susceptible to failure have been analysed numerously $[5,11,12,18]$. Various methods for the rock slope stability analysis are available, namely limit equilibrium method, numerical methods and kinematic methods. Limit equilibrium method is most commonly adopted method to analyse factor of safety due to its simplicity [26, 27].

Hoek and Bray [6] proposed 2D analytical limit equilibrium approach for the calculation of the factor of safety of a plane failure assuming the vertical tension crack and horizontal top surface of sliding mass. Sharma et al. [24] modified the expression considering inclined surface of sliding mass and tension crack. Shukla et al. [25] derived the expression for factor of safety of anchored rock slope considering surcharge and horizontal seismic effect against plane failure. In earlier studies, importance of vertical seismic component was ignored while many recent studies suggested considering vertical seismic component as it affects stability of slopes significantly, particularly in the case of high horizontal acceleration [9, 17]. Some researchers [2, 8, 22] have also studied the influence of vertical seismic coefficient on slope stability adjacent to plane failure and factor of safety is found to be critical considering seismic coefficient against the direction of gravity. Das and Maheshwari [2] adopted the pseudo static approach to study the influence of vertical seismic coefficient on its stability. Ahmadi and Eslami [1] used an analytical approach in which the effect of water forces was analysed.

Many researchers proposed limit equilibrium approach based on the Mohr-Coulomb's linear shear strength criterion [5, 6, 17, 20, 23, 27]. Although Coulomb's shear criterion has widely been used, it is not satisfactory to consider only peak shear strength criterion for rock material. Coulomb's shear criterion has limitations as: (a) Coulomb's shear criterion implies that a major shear fracture exists at peak strength. However, it is not proven to be general for rock failure. (b) Coulomb's shear criterion also implies a specific direction of shear failure which is not always in good agreement with field observation for rock failure (c) Coulomb's shear criterion considers only the shearing during failure; however, rock generally accounts for both shearing and sliding during its failure. As a result of these reasons, other shear strength criteria are preferred for the analysis of shear failure on discontinuity such as Patton's shear criterion and Barton Bandis shear criterion. However, major limitation of Patton's shear strength criterion is that there is a strong difficulty in identifying the normal stress that determines the rupture of the rock asperities. Due to this limitation, Patton's criterion is not so popularly used for rock slope stability. To overcome this limitation, a limiting criterion is derived for the normal stresses in order to compare the field normal stresses along the failure surface in this study and stability of an idealised rock slope is analysed using Patton's criterion. Patton's shear criterion is used for the study due to its accountability of sliding and shearing phenomena during failure instead of only shearing failure considered by Coulomb's criterion. 
In this study, analytical expression for the factor of safety has been developed based on Patton's shear strength criterion to consider both sliding and shearing along the failure surface under different stress levels. To develop factor of safety model, a basic geometry of rock slope is considered from Hoek and Bray [6]. Effect of practically occurring conditions such as vertical tension crack, water filled up in tension crack, rock anchor stabilising force, surcharge, horizontal and vertical seismic forces have also been considered in developing the deterministic model for factor of safety calculation associated with a planar mode of failure. Slope geometry is analysed as 2-dimensional problem considering unit thickness throughout the slope. A limiting criterion is derived for the normal stresses in order to compare the field normal stresses along the failure surface. Then two factor of safety expressions have been developed for both low and high normal stresses using the limiting criteria of stress along the failure plane. Series of parametric studies have also been conducted to analyse the influence of vertical seismic coefficient on the factor of safety.

List of symbols used in the study

\begin{tabular}{|c|c|c|}
\hline Symbol & Definition & Unit \\
\hline A & Base area of sliding rock mass & $\mathrm{m}^{2} / \mathrm{m}$ \\
\hline$B$ & Top width from crest to tension crack & $\mathrm{m}$ \\
\hline$c$ & Cohesion of intact rock & $\mathrm{KN} / \mathrm{m}^{2}$ \\
\hline$c^{*}$ & Cohesion of intact rock in non-dimensional form & \\
\hline$F_{i}$ & Forces which induces sliding & $\mathrm{KN} / \mathrm{m}$ \\
\hline$F_{r}$ & Forces which endure sliding & $\mathrm{KN} / \mathrm{m}$ \\
\hline FS & Factor of safety of rock slope & \\
\hline H & Height of rock slope & $\mathrm{m}$ \\
\hline 9 & Surcharge & $\mathrm{KN} / \mathrm{m}^{2}$ \\
\hline$q^{*}$ & Surcharge in non-dimensional form & \\
\hline$T$ & Rock anchor stabilizing force & $\mathrm{KN} / \mathrm{m}$ \\
\hline$T^{*}$ & Rock anchor stabilizing force in non-dimensional form & \\
\hline$u$ & Water pressure along the failure plane & $\mathrm{KN} / \mathrm{m}$ \\
\hline V & Pressure exerted by water in the tension crack & $\mathrm{KN} / \mathrm{m}$ \\
\hline W & Weight of sliding rock mass & $\mathrm{KN} / \mathrm{m}$ \\
\hline$z$ & Depth of tension crack & $\mathrm{m}$ \\
\hline$z^{*}$ & Depth of tension crack in non-dimensional form & \\
\hline$z_{w}$ & Depth of water filled up in tension crack & $\mathrm{m}$ \\
\hline$z_{w}^{*}$ & Depth of water filled up in tension crack in non-dimensional form & \\
\hline$a_{h}$ & Horizontal seismic acceleration coefficient & \\
\hline$a_{v}$ & Vertical seismic acceleration coefficient & \\
\hline$\Psi_{f}$ & Angle of slope face with horizontal & Degree \\
\hline$\Psi_{p}$ & Angle of failure plane with horizontal & Degree \\
\hline$\theta$ & $\begin{array}{l}\text { Inclination angle of rock anchor stabilizing force with the normal to failure } \\
\text { plane }\end{array}$ & Degree \\
\hline$\gamma_{r}$ & Unit weight of rock & $\mathrm{KN} / \mathrm{m}^{3}$ \\
\hline$\gamma_{w}$ & Unit weight of water & $\mathrm{KN} / \mathrm{m}^{3}$ \\
\hline$\gamma^{*}$ & Unit weight of rock in non-dimensional form & \\
\hline$\varphi_{b}$ & Basic friction angle & Degree \\
\hline$\varphi_{r}$ & Residual friction angle & Degree \\
\hline$i$ & Angle of inclination & Degree \\
\hline$\sigma_{n}$ & Normal stresses along sliding plane & $\mathrm{KN} / \mathrm{m}^{2}$ \\
\hline$\tau$ & Shear stresses along sliding plane & $\mathrm{KN} / \mathrm{m}^{2}$ \\
\hline
\end{tabular}




\section{Limit equilibrium model}

Figure 1 shows an idealised rock slope of height $H$ inclined at an angle $\Psi_{f}$ with horizontal. In Fig. 1, PQRS shows an unstable rock mass of weight $W$ with failure plane at an angle $\Psi_{p}$ with horizontal, anchored rock bolt (Rock anchor stabilizing force $T$ ) inclined at an angle $\theta$ from the normal to the failure plane, carrying a surcharge $q$ over width $B$ at the top of rock slope. The unstable rock mass is subjected to gravitational acceleration induced by earthquake and is bounded at its back by a tension crack $(R Q)$ of depth $z$ filled with water up to depth $z_{w}$. PS and $P Q$ are the slope face and toe failure surface respectively. $V$ shows the pressure exerted by filled up water in tension crack. $U$ shows the hydrostatic uplift pressure exerted by filled-up water along the failure plane. $\alpha_{h}$ and $\alpha_{v}$ are the horizontal seismic coefficient and vertical seismic coefficient respectively.

Hoek and Bray [6] developed a factor of safety model of rock slope considering planar failure using Mohr-Coulomb shear strength linear criterion. Coulomb considered the smooth surface of asperities in determining the friction angle along the rock joints. In hard rock, the surface of discontinuities is never as smooth as considered by Coulomb [6]. As already mentioned, failure along the discontinuities is due to both sliding and shearing. Patton [19] considered the saw tooth surface of rock specimen to simulate the asperities and to determine the friction angle. Patton considered two failure modes, pure sliding at low normal stresses and shearing at high normal stresses. At low normal stress, sliding on inclined tooth face results in dilation of rock mass associated with rotation of blocks. Cohesion is negligible at low normal stresses and friction angle is high as the undulation at sliding surface of rock joint is accounted. With the increase in normal stresses, dilation is suppressed and shearing of intact rock commences. It results in relatively higher cohesion and lower friction angle. Patton proposed the shear strength criterion as

$$
\tau=\sigma_{n} \tan \left(\phi_{b}+i\right) \text { (for low normal stress) }
$$

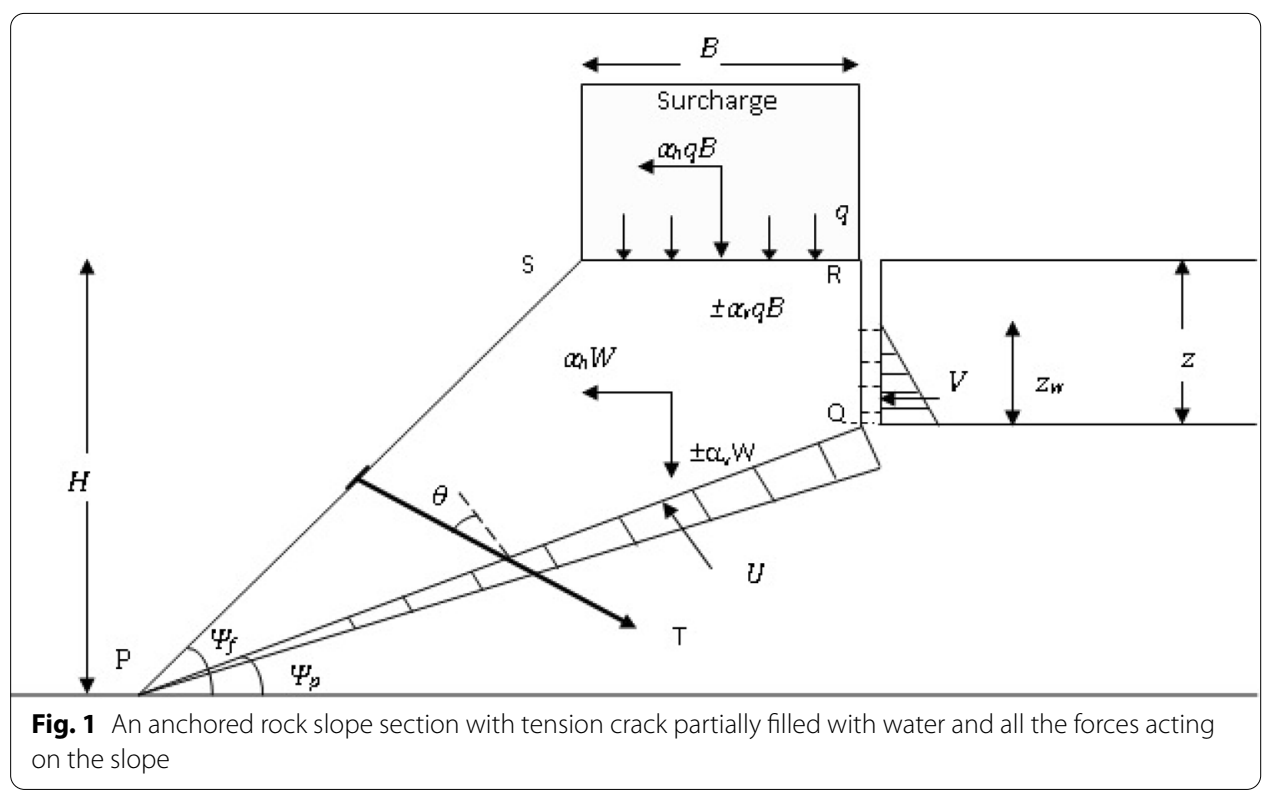




$$
\tau=c+\sigma_{n} \tan \left(\phi_{r}\right)(\text { for high normal stress })
$$

where, $\sigma_{n}$ is the normal stress acting on the failure plane. $\phi_{b}$ is the basic friction angle, $i$ is the inclination angle of asperities along failure plane, $c$ is the apparent cohesion along asperities, $\phi_{r}$ is the residual friction angle. Shear parameters $c, \phi_{b}$ and $\phi_{r}$ can be obtained by direct shear test as suggested by Patton on saw tooth specimen. Inclination angle of asperities $i$ can be measured as angle of saw tooth face of the specimen to horizontal Fig. 2.

As already mentioned, Patton's model has a limitation that there is no clear division between low and high normal stress. In this study, by comparing Eq. 1 and 2, a limiting criterion for normal stress is developed as

$$
\left(\sigma_{n}\right)_{\lim }=\frac{c}{\tan \left(\phi_{b}+i\right)-\tan \phi_{r}}
$$

$\left(\sigma_{n}\right)_{\text {lim }}$ is the limiting value of normal stress along failure plane.

Based on this limiting criterion, this study considered two cases as field normal stress along the failure plane is (1) less than limit value of normal stress using Eqs. (3) and (2) more than limit value of normal stress using Eq. (3).

Factor of safety $(F S)$ of rock slope, FS [6],

$$
F S=\frac{\text { Resisting force }\left(F_{r}\right)}{\text { Driving force }\left(F_{i}\right)}
$$

$F_{r}$ is the summation of forces which resists sliding and $F_{i}$ is the summation of forces which induces sliding.

\section{Case 1: Normal stress along the failure plane is less than the limiting value of normal stress}

Resisting force $F_{r}=\tau A$

Using Patton's shear strength criterion for low stress,

Resisting force $F_{r}=\left[\sigma_{n} \tan \left(\phi_{b}+i\right)\right] A$

From Fig. 1, the total resisting force,

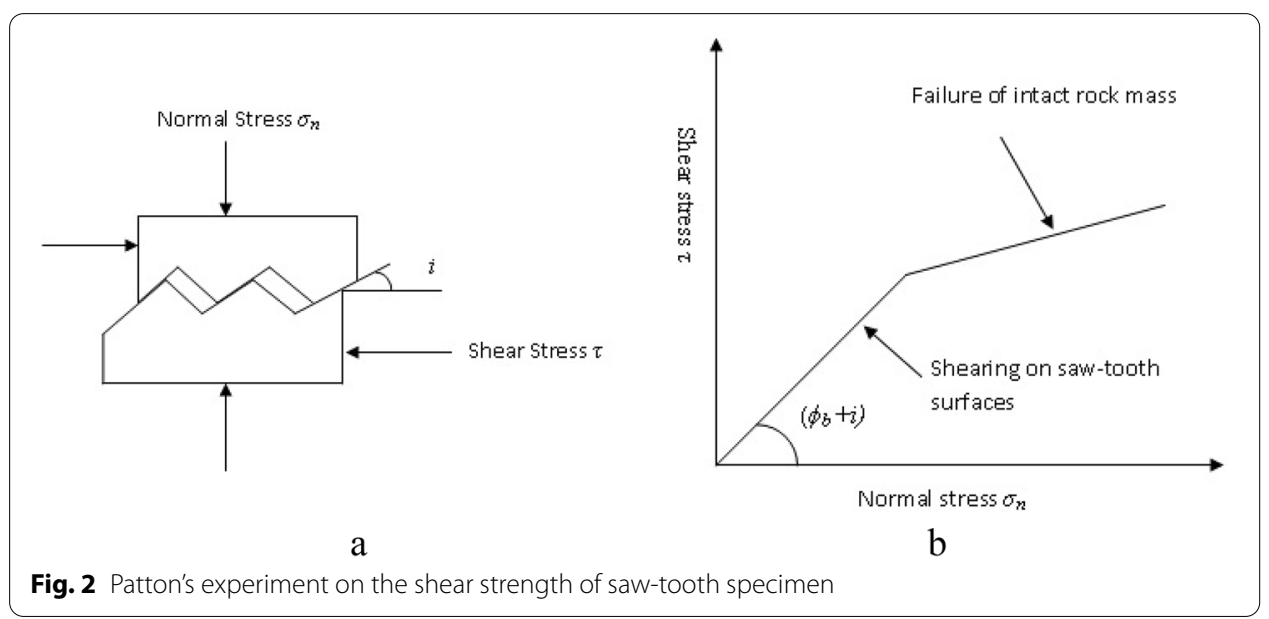




$$
F_{r}=\left[\left[(W+q B)\left\{\left(1 \pm \alpha_{v}\right) \cdot \cos \psi_{p}-\alpha_{h} \sin \psi_{p}\right\}-V \sin \psi_{p}-U+T \cos \theta\right] \tan \left(\phi_{b}+i\right)\right] \times A
$$

where, $A$ is the base area of sliding rock mass.

Total forces which induce sliding,

$$
F_{i}=(W+q B)\left\{\left(1 \pm \alpha_{v}\right) \cdot \sin \psi_{p}-\alpha_{h} \cos \psi_{p}\right\}+V \cos \psi_{p}-T \sin \theta
$$

Combining Eqs. (4), (5) and (6)

$$
F S=\frac{\left[(W+q B)\left\{\left(1 \pm \alpha_{v}\right) \cdot \cos \psi_{p}-\alpha_{h} \sin \psi_{p}\right\}-V \sin \psi_{p}-U+T \cos \theta\right] \tan \left(\phi_{b}+i\right)}{(W+q B)\left\{\left(1 \pm \alpha_{v}\right) \sin \psi_{p}-\alpha_{h} \cos \psi_{p}\right\}+V \cos \psi_{p}-T \sin \theta}
$$

From Fig. 1, the expression for $W, B, V$ and $U$ can be derived as

$$
\begin{aligned}
& W=\frac{1}{2} \gamma_{r} H^{2}\left[\left\{1-\left(\frac{z}{h}\right)^{2}\right\} \cot \psi_{p}-\cot \psi_{f}\right] \\
& B=(H-z) \cot \psi_{p}-H \cot \psi_{f} \\
& V=\frac{1}{2} \gamma_{w} z_{w}^{2} \\
& U=\frac{1}{2} \gamma_{w} z_{w}(H-z) \operatorname{cosec} \psi_{p}
\end{aligned}
$$

where, $\gamma_{r}$ is the unit weight of rock and $\gamma_{w}$ is the unit weight of water.

Combining Eqs. (7) and (8a, 8b, 8c and 8d)

$$
F S=\frac{\left[\begin{array}{c}
{\left[\frac{1}{2} \gamma_{r} H^{2}\left[\left\{1-\left(\frac{z}{H}\right)^{2}\right\} \cot \psi_{p}-\cot \psi_{f}\right]+q\left\{(H-z) \cot \psi_{p}-H \cot \psi_{f}\right\}\right] *\left\{\left(1 \pm \alpha_{v}\right) \cdot \cos \psi_{p}-\alpha_{h} \sin \psi_{p}\right\}} \\
-\frac{1}{2} \gamma_{w} z_{w}^{2} \sin \psi_{p}-\frac{1}{2} \gamma_{w} z_{w}(H-z) \operatorname{cosec} \psi_{p}+T \cos \theta
\end{array}\right] \tan \left(\phi_{b}+i\right)}{\left[\frac{1}{2} \gamma_{r} H^{2}\left[\left\{1-\left(\frac{z}{H}\right)^{2}\right\} \cot \psi_{p}-\cot \psi_{f}\right]+q\left\{(H-z) \cot \psi_{p}-H \cot \psi_{f}\right\}\right]\left\{\left(1 \pm \alpha_{v}\right) \cdot \sin \psi_{p}+\alpha_{h} \cos \psi_{p}\right\}}
$$

Equation (9) presents the factor of safety expression of rock slope for the considered combination of forces including the horizontal and vertical seismic inertia forces. For the ease of parametric study, this equation of factor of safety has been converted into non-dimensional form by dividing the numerator and denominator by $\gamma_{r} \mathrm{H}^{2}$.

$$
F S=\frac{\left[\begin{array}{c}
{\left[\frac{1}{2} \gamma_{r} H^{2}\left[\left\{1-\left(\frac{z}{H}\right)^{2}\right\} \cot \psi_{p}-\cot \psi_{f}\right]+q\left\{(H-z) \cot \psi_{p}-H \cot \psi_{f}\right\}\right] *\left\{\left(1 \pm \alpha_{\nu}\right) \cdot \cos \psi_{p}-\alpha_{h} \sin \psi_{p}\right\}} \\
-\frac{1}{2} \gamma_{w} z_{w}^{2} \sin \psi_{p}-\frac{1}{2} \gamma_{w} z_{w}(H-z) \operatorname{cosec} \psi_{p}+T \cos \theta
\end{array}\right] \tan \left(\phi_{b}+i\right)}{\left[\frac{1}{2} \gamma_{r} H^{2}\left[\left\{1-\left(\frac{z}{H}\right)^{2}\right\} \cot \psi_{p}-\cot \psi_{f}\right]+q\left\{(H-z) \cot \psi_{p}-H \cot \psi_{f}\right\}\right]\left\{\left(1 \pm \alpha_{v}\right) \cdot \sin \psi_{p}+\alpha_{h} \cos \psi_{p}\right\}}
$$

where, $z^{*}=\frac{z}{H}, q^{*}=\frac{q}{\gamma H}, z_{w}^{*}=\frac{z_{w}}{H}, \gamma^{*}=\frac{\gamma_{r}}{\gamma_{w}}, q^{*}=\frac{q}{\gamma H}, T^{*}=\frac{T}{\gamma H^{2}}$

Equation (10) presents the factor of safety expression for rock slope with the considered parameters in the non-dimensional forms for low normal stress. 


\section{Case 2: Normal stress along the failure plane is more than limit value of normal stress}

Using Patton's shear strength criterion for high stress,

Resisting force, $F_{r}=\left[c+\sigma_{n} \tan \left(\phi_{r}\right)\right] A$

From Fig. 1, the total resisting force,

$$
F_{r}=c A+\left[(W+q B)\left\{\left(1 \pm \alpha_{v}\right) \cdot \cos \psi_{p}-\alpha_{h} \sin \psi_{p}\right\}-V \sin \psi_{p}-U+T \cos \theta\right] \tan \phi_{r}
$$

Combining Eqs. (4), (6) and (11)

$$
F S=\frac{c A+\left[(W+q B)\left\{\left(1 \pm \alpha_{v}\right) \cdot \cos \psi_{p}-\alpha_{h} \sin \psi_{p}\right\}-V \sin \psi_{p}-U+T \cos \theta\right] \tan \left(\phi_{r}\right)}{(W+q B)\left\{\left(1 \pm \alpha_{v}\right) \cdot \sin \psi_{p}-\alpha_{h} \cos \psi_{p}\right\}+V \cos \psi_{p}-T \sin \theta}
$$

where

$$
A=(H-z) \operatorname{cosec} \psi_{p}
$$

Combining Eqs. (8a, 8b, 8c and 8d), (12) and (13)

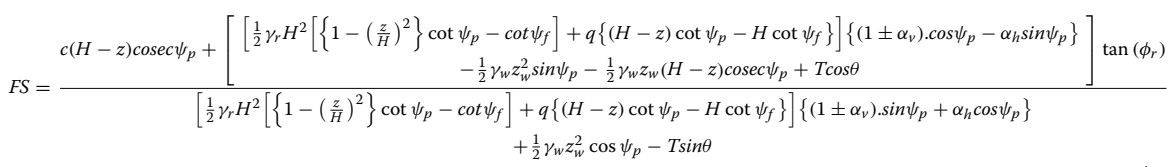

Equation (14) presents the factor of safety expression for the rock slope for the considered combination of forces for high normal stress. Again, for the ease of parametric study this equation of factor of safety has been converted into non-dimension form by dividing the numerator and denominator by $\gamma_{\mathrm{r}} \mathrm{H}^{2}$

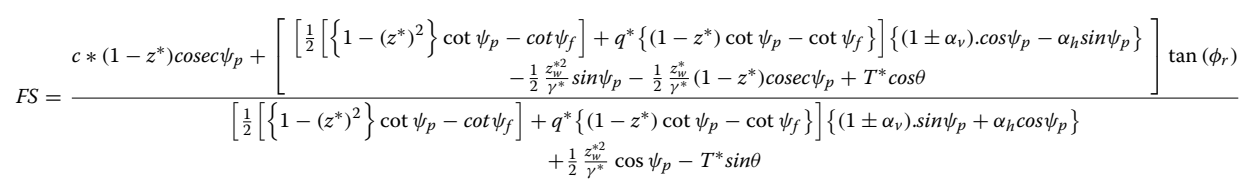

where, $z^{*}=\frac{z}{H}, q^{*}=\frac{q}{\gamma H}, z_{w}^{*}=\frac{z_{w}}{H}, \gamma^{*}=\frac{\gamma_{r}}{\gamma_{w}}, q^{*}=\frac{q}{\gamma H}, T^{*}=\frac{T}{\gamma H^{2}}$

Equation (15) presents the factor of safety expression for the rock slope with the considered parameters in their non-dimensional forms for high normal stress. This expression can be utilized to study the influence of any particular parameter on the stability of rock slope.

\section{Special cases}

When there is no water in the tension crack, surcharge, stabilizing force and seismic force. $\left(z_{w}=0, q=0, T=0, \alpha_{h}=0, \alpha_{v}=0\right)$.

$$
F S=\frac{\tan \left(\phi_{b}+i\right)}{\tan \psi_{p}}(\text { for low normal stress })
$$




$$
F S=\frac{c(H-z) \operatorname{cosec} \psi_{p}+\left[\frac{1}{2} \gamma_{r} H^{2}\left[\left\{1-\left(\frac{z}{H}\right)^{2}\right\} \cot \psi_{p}-\cot \psi_{f}\right]\right] \cos \psi_{p} \tan \left(\phi_{r}\right)}{\left[\frac{1}{2} \gamma_{r} H^{2}\left[\left\{1-\left(\frac{z}{H}\right)^{2}\right\} \cot \psi_{p}-\cot \psi_{f}\right]\right] \sin \psi_{p}} \text { (for high normal stress) }
$$

When there is no water in tension crack, surcharge, stabilizing force $\left(z_{w}=0, q=0\right.$, $T=0)$

$$
\begin{aligned}
& F S=\frac{\left\{\left(1 \pm \alpha_{v}\right) \cos \psi_{p}-\alpha_{h} \sin \psi_{p}\right\} \tan \left(\phi_{b}+i\right)}{\left\{\left(1 \pm \alpha_{v}\right) \sin \psi_{p}-\alpha_{h} \cos \psi_{p}\right\}} \text { (for low normal stress) } \\
& F S=\frac{c(H-z) \operatorname{cosec} \psi_{p}+\left[\left[\frac{1}{2} \gamma_{r} H^{2}\left[\left\{1-\left(\frac{z}{H}\right)^{2}\right\} \cot \psi_{p}-\cot \psi_{f}\right]\right]\left\{\left(1 \pm \alpha_{v}\right) \cos \psi_{p}-\alpha_{h} \sin \psi_{p}\right\}\right] \tan \left(\phi_{r}\right)}{\left[\frac{1}{2} \gamma_{r} H^{2}\left[\left\{1-\left(\frac{z}{H}\right)^{2}\right\} \cot \psi_{p}-\cot \psi_{f}\right]\right]\left\{\left(1 \pm \alpha_{v}\right) \sin \psi_{p}+\alpha_{h} \cos \psi_{p}\right\}} \text { (for high normal stress) }
\end{aligned}
$$

When there is no water in tension crack, surcharge and seismic forces $\left(z_{w}=0, q=0\right.$, $\alpha_{h}=0, \alpha_{v}=0$ )

$$
\begin{aligned}
& F S=\frac{\left[\frac{1}{2} \gamma_{r} H^{2}\left[\left\{1-\left(\frac{z}{H}\right)^{2}\right\} \cot \psi_{p}-\cot \psi_{f}\right] \cos \psi_{p}+T \cos \theta\right] \tan \left(\phi_{b}+i\right)}{\frac{1}{2} \gamma_{r} H^{2}\left[\left\{1-\left(\frac{z}{H}\right)^{2}\right\} \cot \psi_{p}-\cot \psi_{f}\right] \sin \psi_{p}-T \sin \theta} \text { (for low normal stress) } \\
& F S=\frac{c(H-z) \operatorname{cosec} \psi_{p}+\left[\frac{1}{2} \gamma_{r} H^{2}\left[\left\{1-\left(\frac{z}{H}\right)^{2}\right\} \cot \psi_{p}-\cot \psi_{f}\right] \cos \psi_{p}+T \cos \theta\right] \tan \left(\phi_{r}\right)}{\frac{1}{2} \gamma_{r} H^{2}\left[\left\{1-\left(\frac{z}{H}\right)^{2}\right\} \cot \psi_{p}-\cot \psi_{f}\right] \sin \psi_{p}-T \sin \theta} \text { (for high normal stress) }
\end{aligned}
$$

When there are no seismic forces. $\left(\alpha_{h}=0, \alpha_{v}=0\right)$

$$
F S=\frac{\left[\left\lfloor\frac{1}{2} \gamma_{r} H^{2}\left[\left\{1-\left(\frac{z}{H}\right)^{2}\right\} \cot \psi_{p}-\cot \psi_{f}\right]+q\left\{(H-z) \cot \psi_{p}-H \cot \psi_{f}\right\}\right] \cos \psi_{p}-\frac{1}{2} \gamma_{w} z_{w}^{2} \sin \zeta_{p}-\frac{1}{2} \gamma_{w} z_{w}(H-z) \operatorname{cosec} \psi_{p}+T \cos \theta\right] \tan \left(\phi_{b}+i\right)}{\left[\frac{1}{2} \gamma_{r} H^{2}\left[\left\{1-\left(\frac{z}{H}\right)^{2}\right\} \cot \psi_{p}-\cot \psi_{f}\right]+q\left\{(H-z) \cot \psi_{p}-H \cot \psi_{f}\right\}\right] \sin \psi_{p}+\frac{1}{2} \gamma_{w} z_{w}^{2} \cos \psi_{p}-T \sin \theta}
$$

Table 1 Ranges for the parameters considered in the study [8]

\begin{tabular}{lllll}
\hline SI. No & Parameter & Range & Value used for case 1 & $\begin{array}{l}\text { Value } \\
\text { used } \\
\text { for case 2 }\end{array}$ \\
\hline 1 & & & $50^{\circ}$ \\
2 & $\Psi_{f}$ & $40^{\circ}-55^{\circ}$ & $50^{\circ}$ & $35^{\circ}$ \\
3 & $\Psi_{p}$ & $35^{\circ}-45^{\circ}$ & $35^{\circ}$ & 0.1 \\
4 & $c^{*}$ & $0.04-0.16$ & - & - \\
5 & $\varphi_{b}$ & $20^{\circ}-40^{\circ}$ & $25^{\circ}$ & $15^{\circ}$ \\
6 & $\varphi_{r}$ & $0-20^{\circ}$ & - & 2.5 \\
7 & $\gamma^{*}$ & $2.0-3.0$ & 2.5 & 0.1 \\
8 & $z^{*}$ & $0.05-0.25$ & 0.1 & 0.05 \\
9 & $z_{w}^{*}$ & $0-0.1$ & 0.05 & 0.5 \\
10 & $q^{*}$ & $0-1.5$ & 0.1 & 0.1 \\
11 & $T^{*}$ & $0-0.15$ & 0.05 & $45^{\circ}$ \\
12 & $\theta$ & $0-80^{\circ}$ & $45^{\circ}$ & 0.2 \\
13 & $a_{h}$ & $0.05-0.3$ & 0.2 & 0.1 \\
14 & $a_{v}$ & $-0.15-0.15$ & 0.1 & - \\
\hline
\end{tabular}


$F S=$

$\frac{c(H-z) \operatorname{cosec} \psi_{p}+\left[\left[\frac{1}{2} \gamma_{r} H^{2}\left[\left\{1-\left(\frac{z}{H}\right)^{2}\right\} \cot \psi_{p}-\cot \psi_{f}\right]+q\left\{(H-z) \cot \psi_{p}-H \cot \psi_{f}\right\}\right] \cos \psi_{p}-\frac{1}{2} \gamma_{w} z_{w}^{2} \sin \psi_{p}-\frac{1}{2} \gamma_{w} z_{w}(H-z) \operatorname{cosec} \psi_{p}+T \cos \theta\right] \tan \left(\phi_{r}\right)}{\left[\frac{1}{2} \gamma_{r} H^{2}\left[\left\{1-\left(\frac{z}{H}\right)^{2}\right\} \cot \psi_{p}-\cot \psi_{f}\right]+q\left\{(H-z) \cot \psi_{p}-H \cot \psi_{f}\right\}\right] \sin \psi_{p}+\frac{1}{2} \gamma_{w} z_{w}^{2} \cos \psi_{p}-T \sin \theta}$ (for high normal stress)

\section{Illustrative example}

The main influential factors for the stability of rock slopes are geometry of rock slopes (angle of slope face, angle of failure plane, height of slope, and depth of tension crack), cohesion, peak and residual angle of internal friction, inclination of rock discontinuities, drainage condition, and external forces such as rainfall, seismicity and of course the different man-made activities over the slope $[1,5,7,15,24]$. Characterization of these geometrical parameters is quite simple. These can be defined by field mapping. Determination of water depth and seismic acceleration is relatively difficult in rock slope evaluation because these parameters do not have single fixed value. Different parametric analyses have thus been carried out to study the influence of vertical seismic coefficient on the stability of rock slope considering the practical possible range of parameters in their non-dimensional form as given in Table 1. These ranges of parameters considered in this study are taken from the previous studies made by Hossain et al. [8] and Shukla et.al. [25].

While performing the different parametric studies, values for the parameters which are kept constant in a particular study are taken from the listed values for case 1 and case 2 in the Table 1 and for the parameter, of which the influence on factor of safety is to be studied, the listed range in the Table 1 has been considered. Two of the parameters value $\mathrm{q}^{*}$ and $\mathrm{T}^{*}$ are kept different in case 1 and case 2 , in order to study of low stress and high stress conditions along the failure plane respectively.

Horizontal seismic coefficient is taken as per the suggestion of various authors summarised by Kramer [15]. The horizontal seismic forces are considered to act outward of the slope i.e. in the direction of failure of slope. Horizontal seismic coefficient is always positive. While the vertical seismic coefficient can be positive and negative. Positive and negative vertical seismic coefficient represents vertical seismic forces directed towards and opposite to the direction of gravity respectively. In addition to the direction, magnitude of seismic forces is also varied.

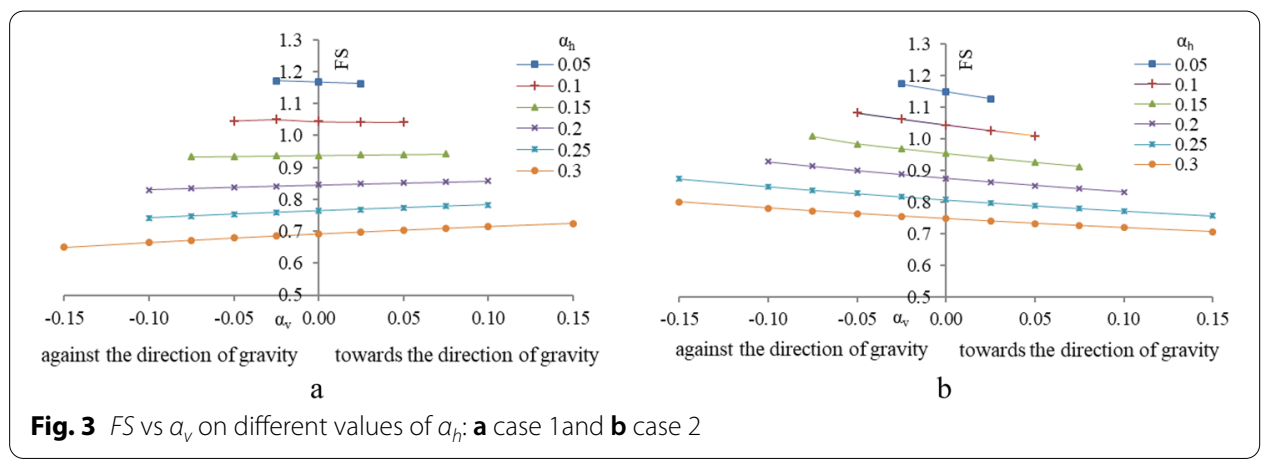




\section{Results and discussion}

In the following sections, results are presented in the graphical form for $F S$ vs $\alpha_{v}$ with varying parameters. Studies 1-9 show the analysis of the variation of factor of safety $(F S)$ with vertical seismic coefficient for different values of horizontal seismic coefficient $\left(\alpha_{v}\right)$, angle of inclination of slope face $\left(\Psi_{f}\right)$, angle of inclination of failure plane $\left(\Psi_{p}\right)$, depth of tension crack $\left(z^{*}\right)$, depth of water in tension crack $\left(z_{w}^{*}\right)$, unit weight of rock $\left(\gamma^{*}\right)$, surcharge $\left(q^{*}\right)$, anchor stabilising force $\left(T^{*}\right)$, angle of inclination of rock anchor stabilising force to the normal at the failure plane $(\theta)$, in their non dimensional form for low (case 1 ) and high (case 2) normal stresses, respectively. Study 10 shows the analysis of the variation of factor of safety with vertical seismic coefficient for different values of basic frictional angle $\left(\phi_{b}\right)$ for case 1 , and for different values of residual frictional angle $\left(\phi_{r}\right)$ for case 2 . Study 11 shows the analysis of the variation of factor of safety with vertical seismic coefficient for different values of inclination angle of asperities along failure plane $(i)$ for case 1 and for different values of cohesion $(c)$ for case 2 .

\section{Study 1: Effect of $a_{v}$ on FS for different $a_{h}$}

In this section, as recommended by several researchers, it is studied that how the factor of safety of the considered rock slope can vary with the vertical seismic acceleration coefficient $\left(\alpha_{v}\right)$ for different value of horizontal seismic coefficient $\left(\alpha_{h}\right)$ and whether the change is significant or not.

As already mentioned, Fig. 3 presents the results of the study for different value of $\alpha_{h}$ as $0.05,0.1,0.15,0.2,0.25,0.3$ considering specific set of influential parameters in their non-dimensional form as $\Psi_{f}=50^{\circ}, \Psi_{p}=35^{\circ}, z^{*}=0.1, z_{w^{*}}=0.05, \gamma^{*}=2.5, \theta=45^{\circ}$. Two cases have been studied, namely, (a) case 1: $\phi_{b}=25^{\circ}, i=10^{\circ}, q^{*}=0.1, T^{*}=0.05$ and (b) case 2: $c^{*}=0.1, \phi_{r}=15^{\circ}, q^{*}=0.5, T^{*}=0.1$, as also mentioned in Table 1 .

In this study, the vertical seismic coefficient is taken as not more than the half of the horizontal seismic coefficient following IS:1893-2016 [10], where, it is mentioned that the value of vertical seismic coefficient should be taken as half or two-thirds of the horizontal seismic coefficient as usually vertical motion is weaker than the horizontal motion.

It is observed from Fig. 3a that the factor of safety decreases with increase in the values of horizontal seismic coefficient significantly. At $\alpha_{v}=0.0$, the percentage decrease in $F S$ with $\alpha_{h}$, from 0.05 to 0.1 , is nearly $10 \%$. It is also observed that for lower value of $\alpha_{h}$ less than 0.1, FS increases with an increase in the value of $\alpha_{v}$ against the direction of

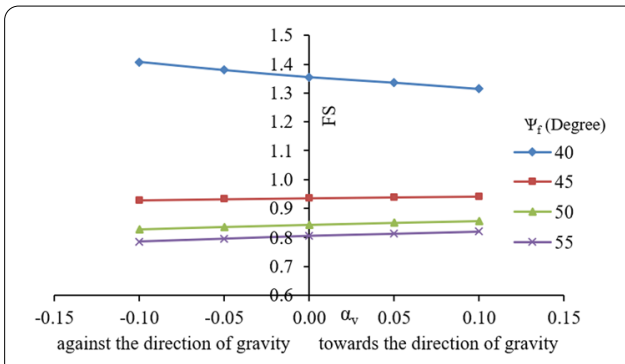

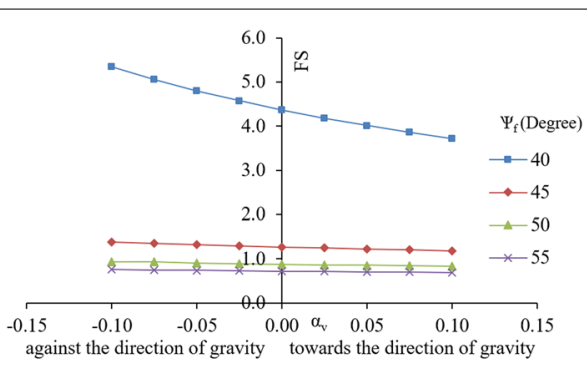

b

Fig. 4 FS vs av on different values of $\Psi$ f: a case 1 and $\mathbf{b}$ case 2 
gravity and decreases with increase in the value of $\alpha_{v}$ towards the direction of gravity although the percentage change is not so significant. For higher value of $\alpha_{h}$ (greater than 0.1 ), FS increases with an increase in the value of $\alpha_{v}$ towards the direction of gravity and decreases with increase in the value of $\alpha_{v}$ against the direction of gravity. As the value of $\alpha_{h}$ increases, variation of $F S$ with $\alpha_{v}$ also increases. Maximum variation of $F S$ with $\alpha_{v}$ is observed at $\alpha_{h}=0.3$. At $\alpha_{h}=0.3$, the percentage change of relative decrease in FS with $\alpha_{v}$, from 0.0 to 0.15 against the direction of gravity is $28.2 \%$ whereas that towards the direction of gravity is $22.07 \%$.

From Fig. 3b, it is noted that the value of FS is greater than unity when the value of $\alpha_{h}$ is smaller than 0.1. Here, the value of FS decreases almost linearly with increase in $\alpha_{v}$ towards the direction of gravity and increases with increase in $\alpha_{v}$ against the direction of gravity, which is just opposite to the earlier case (case 1). This is due to the consideration of the sliding phenomenon along with the discontinuities of rock mass along the failure plane at low stress. But increase of factor of safety against the direction of gravity is more than the rate of decrease of factor of safety towards the direction of gravity. Variation of $F S$ with $\alpha_{v}$ is found to be maximum at $\alpha_{h}=0.3$. At $\alpha_{h}=0.3$, the percentage change of relative decrease in $F S$ with $\alpha_{v}$ from 0.0 to 0.15 towards the direction of gravity is $27.27 \%$, whereas the percentage change of relative increase in $F S$ with $\alpha_{v}$ from 0.0 to 0.15 against the direction of gravity is $35.13 \%$.

\section{Study 2: Effect of $a_{v}$ on FS for different $\Psi_{f}$}

In this study, behaviour of rock slope with vertical seismic coefficient for different values of angle of slope face is of concern. As reported by many researchers [7, 25], the angle of rock slope face affects the slope stability to a great extent due to the fact that factor of safety is inversely proportional to angle of slope face.

Figure 4 presents the results for different value of $\Psi_{f}$ as $40^{\circ}, 45^{\circ}, 50^{\circ}, 55^{\circ}$, keeping other parameters as mentioned in Table 1.

From Fig. $4 \mathrm{a}$, it is observed that $F S$ reduces as $\Psi_{f}$ increases. The rate of reduction in $F S$ is more when $\Psi_{f}$ from $40^{\circ}$ to $45^{\circ}$ and less when $\Psi_{f}$ greater than $45^{\circ}$. For $\Psi_{f}=40^{\circ}$, it is observed that $F S$ reduces with an increase in $\alpha_{v}$ towards the direction of gravity and with the increase in $\alpha_{v}$ against the direction of gravity. For greater value of $\Psi_{f}$ (greater than $\left.40^{\circ}\right)$, FS reduces with increase in $\alpha_{v}$ against the direction of gravity although the variation is insignificant. Maximum variation of factor of safety with $\alpha_{v}$ is observed at $\Psi_{f}=40^{\circ}$. At

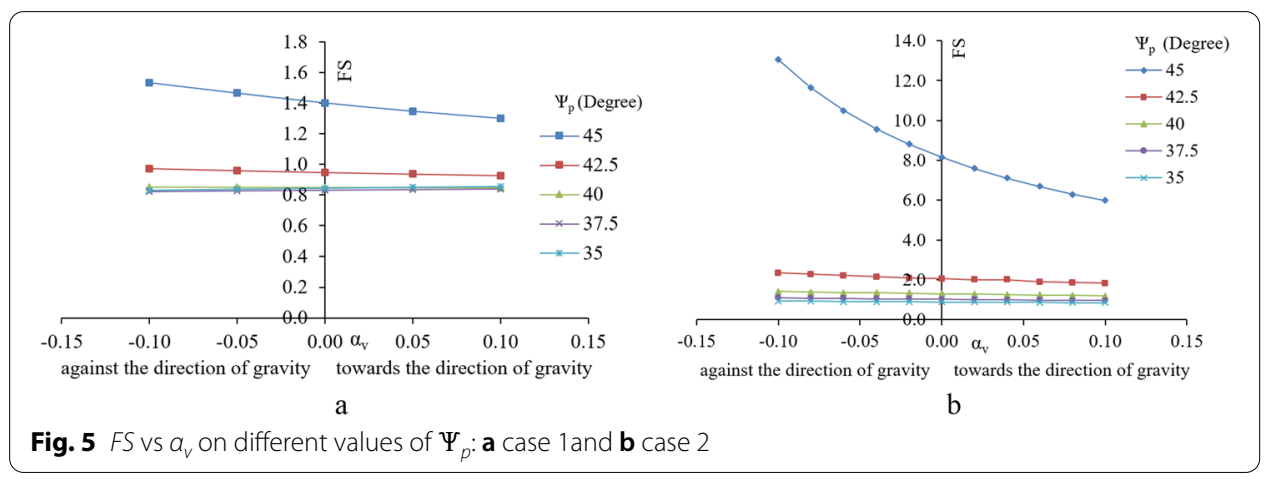


$\Psi_{f}=40^{\circ}$, the percentage change of relative increase in $F S$ with $\alpha_{v}$ from 0.0 to 0.10 against the direction of gravity is $56.33 \%$ whereas that towards the direction of gravity is $38.22 \%$.

From Fig. 4b, it is observed that the factor of safety is very high for $\Psi_{f}=40^{\circ}$. FS decreases as $\Psi_{f}$ increases. FS decreases significantly when $\Psi_{f}$ increases from $40^{\circ}$ to $45^{\circ}$. For the value of $\Psi_{f}=40^{\circ}$, FS varies nonlinearly with the change in the value of $\alpha_{v}$ and decreases with increase in $\alpha_{\nu}$ towards the direction of gravity and increases with increase in $\alpha_{v}$ against the direction of gravity. For $\Psi_{f}$ greater than $45^{\circ}$, FS varies almost linearly with $\alpha_{v}$ and the rate of change of FS with $\alpha_{v}$ is almost insignificant. For $\Psi_{f}$ greater than $50^{\circ}, F S$ becomes less than unity making the rock slope unstable. Maximum variation of $F S$ with $\alpha_{v}$ is observed at $\Psi_{f}=40^{\circ}$. At $\Psi_{f}=40^{\circ}$, the percentage change of relative decrease in $F S$ with $\alpha_{v}$ from 0.0 to 0.1 towards the direction of gravity is $65.13 \%$ and that against the direction of gravity is $22.30 \%$.

From this study, it can be stated as factor of safety of rock slope decreases with increase in angle of inclination of slope face with horizontal as steepness of slope face makes the slope unstable.

\section{Study 3: Effect of $a_{v}$ on FS for different $\Psi_{p}$}

This study focuses on the influence of vertical seismic coefficients on factor of safety for different values of angle of inclination of slope failure plane $\left(\Psi_{p}\right)$.

Figure 5 presents the results for different $\Psi_{p}$ as $45^{\circ}, 42.5^{\circ}, 40^{\circ}, 37.5^{\circ}, 35^{\circ}$ considering specific set of influential parameters in their non-dimensional form as mentioned in Table 1.

From Fig. 5a it is observed that FS decreases as angle of inclination of slope failure decreases. As $\Psi_{p}$ decreases, it means that the weight of sliding rock mass increases. For the lower value of $\Psi_{p}$, FS increases as $\alpha_{v}$ increases towards the direction of gravity and decreases as $\alpha_{v}$ increases against the direction of gravity. However, the rate of variation of $F S$ with $\alpha_{v}$ is almost insignificant.

From Fig. 5b, it is observed that $F S$ decreases as $\alpha_{v}$ increases towards the direction of gravity and increases as $\alpha_{v}$ increases against the direction of gravity. For $\Psi_{p}=45^{\circ}$, variation of $F S$ with $\alpha_{v}$ is nonlinear and rate of increase with $\alpha_{v}$ against the direction of gravity is much higher than the rate of decrease with $\alpha_{v}$ towards the direction of gravity. $F S$ is greater than unity for all the values of $\Psi_{p}$ greater than $40^{\circ}$. For $\Psi_{p}$ less than $40^{\circ}$, the rate of change of $F S$ with vertical seismic coefficient is again

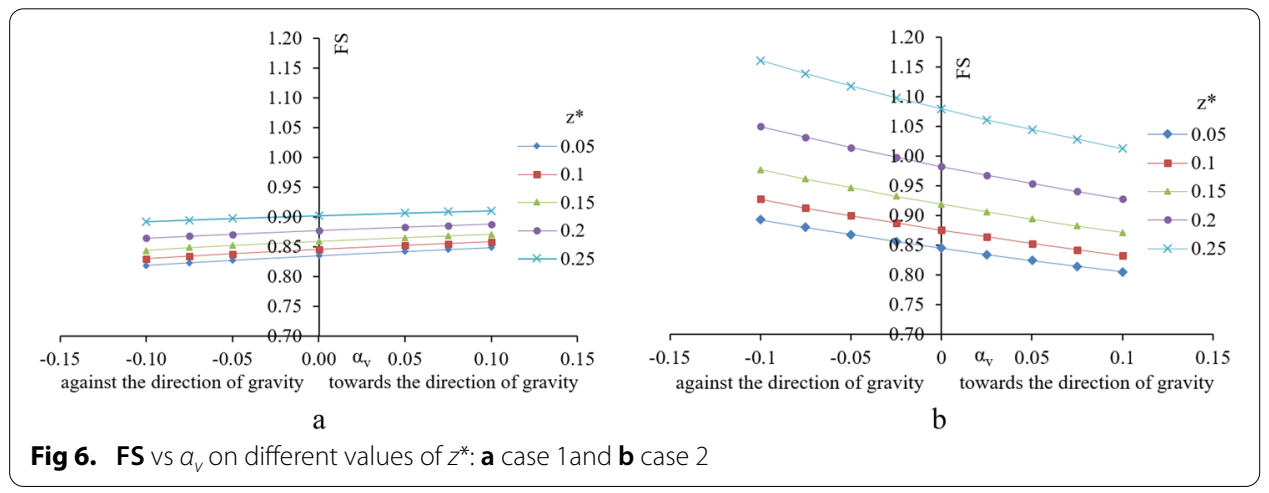


insignificant. Variation of $F S$ is found to be maximum at $\Psi_{p}=45^{\circ}$. At $\Psi_{p}=45^{\circ}$, the percentage change of relative decrease in $F S$ with $\alpha_{v}$ from 0.0 to 0.1 towards the direction of gravity is $26.83 \%$ and that against the direction of gravity is $60.27 \%$.

From this study it is observed that factor of safety of rock slope increases with increase in angle of slope failure plane with horizontal as the weight of rock mass along the sliding plane reduces with increase in inclination angle of failure plane to horizontal.

\section{Study 4: Effect of $a_{v}$ on FS for different $z^{*}$}

This study presents the variation of factor of safety with vertical seismic coefficients for different value of depth of tension crack $\left(z^{*}\right)$.

Figure 6 presents the results for different $z^{*}$ as $0.05,0.10,0.15,0.20,0.25$ considering a specific set of influential parameters in their non-dimensional form as mentioned in Table 1

From Fig. 6a, it is observed that $F S$ increases as the depth of tension crack increases. It is due to geometrical changes in the sliding rock mass over failure plane.

FS increases with an increase in $\alpha_{v}$ towards the direction of gravity and decreases with increase in $\alpha_{v}$ against the direction of gravity although the amount of variation of $F S$ with $\alpha_{v}$ is not so significant. But the rate of decrease in $F S$ with increase in $\alpha_{v}$ against the direction of gravity is more than the rate of increase in $F S$ with increase in $\alpha_{v}$ towards the direction of gravity. Variation of $F S$ with $\alpha_{v}$ is found to be maximum at $z^{*}=0.05$. At $z^{*}=0.05$, the percentage change of relative decrease in $F S$ with $\alpha_{v}$ from 0.0 to 0.15 against the direction of gravity is $16.3 \%$ whereas that towards the direction of gravity is $13.7 \%$.

From Fig. 6b, it is observed that FS decreases with an increase in the value of $\alpha_{v}$ towards the direction of gravity and increases with increase in $\alpha_{v}$ against the direction of gravity almost linearly for the considered value of depth of tension crack. Here again $F S$ increases as the depth of tension crack $\left(z^{*}\right)$ increases. $F S$ is greater than unity for $z^{*}$ greater or equals to 0.25 . Variation of $F S$ with $\alpha_{v}$ increases as $z^{*}$ increases. For $z^{*}=0.25$, the percentage change of relative decrease in FS with $\alpha_{v}$ from 0.0 to 0.10 towards the direction of gravity is $66.63 \%$ and that against the direction of gravity is 81.88\%.

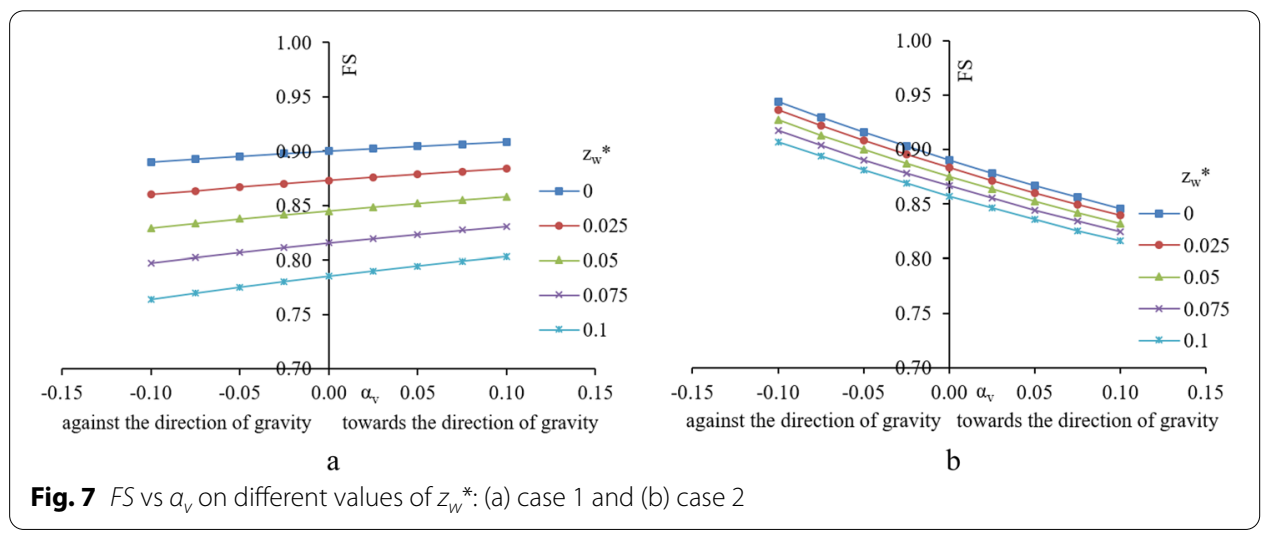



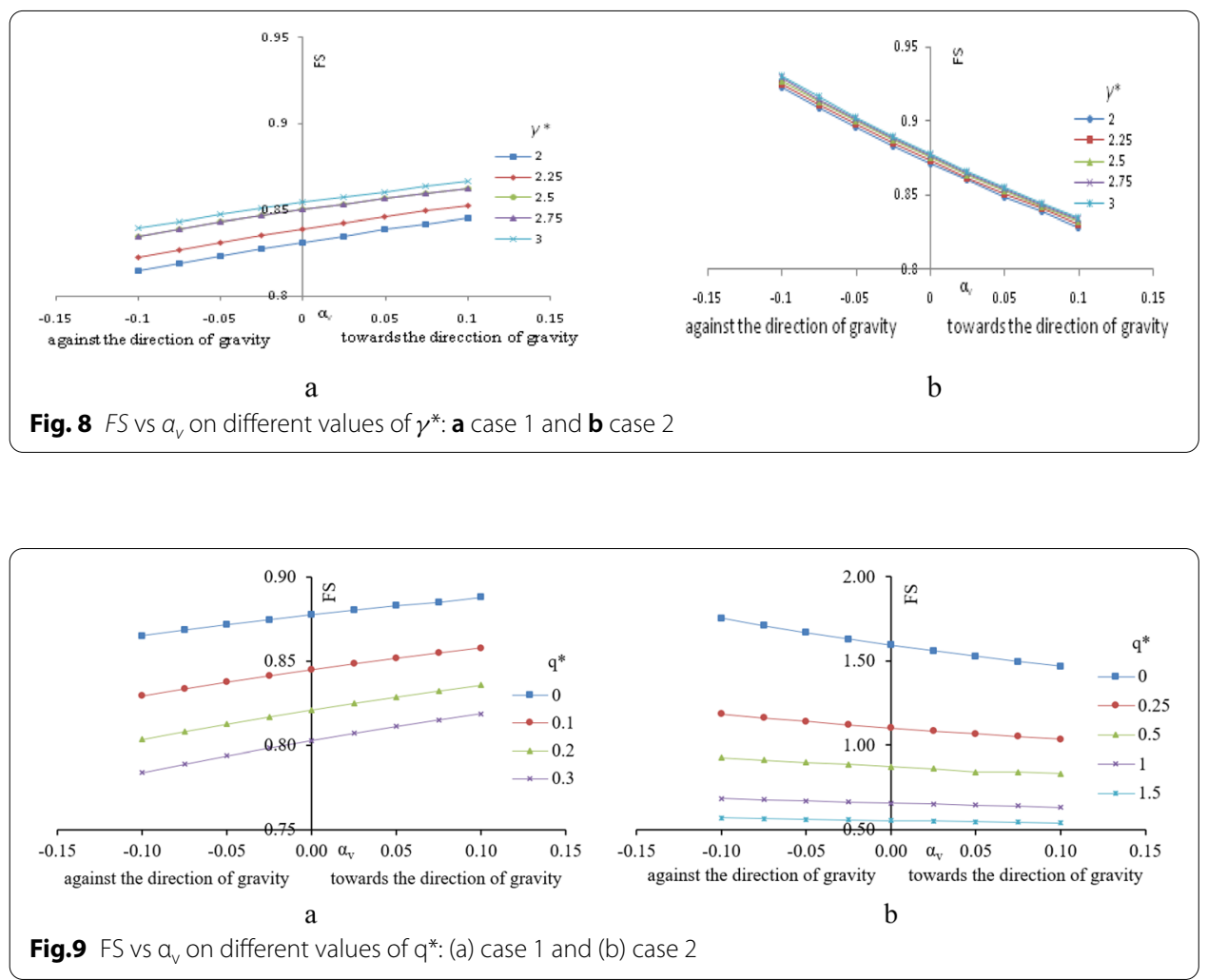

\section{Study 5: Effect of $a_{v}$ on FS for different $z_{w}{ }^{*}$}

This study presents the variation of factor of safety with vertical seismic coefficient $\left(\alpha_{v}\right)$ for different value of depth of water in tension crack $\left(z_{w}{ }^{*}\right)$. This study is conducted to know how different depth of water in tension crack affects in $F S$ with different vertical acceleration coefficient.

Figure 7 presents the results for different $z_{w}{ }^{*}$ as $0.0,0.025,0.05,0.075,0.10$ considering a specific set of influential parameters in their non-dimensional form as mentioned in Table 1.

It is observed from Fig. 7 that, FS reduces with an increase in depth of water in tension crack. Water present in tension crack forces the surface of discontinuity apart, as hydrostatic pressure act in the direction of movement of sliding block. From Fig. 7a, it is also observed that the $F S$ increases with increase in $\alpha_{v}$ towards the direction of gravity and decreases against the direction of gravity almost linearly. Variation of FS is found to be maximum at $z_{w}=0.1$. At $z_{w}=0.1$, the percentage change of relative decrease in FS with $\alpha_{v}$ from 0.0 to 0.15 against the direction of gravity is $21.3 \%$ whereas the percentage change of relative increase in $F S$ with $\alpha_{v}$ from 0.0 to 0.15 that towards the direction of gravity is $17.8 \%$.

From Fig. 7b, it is observed that $F S$ is higher for smaller value of $z_{w}{ }^{*}$. FS decreases with increase in $\alpha_{v}$ towards the direction of gravity and increases with increase in $\alpha_{v}$ against the direction of gravity almost linearly. At $z_{w}{ }^{*}=0.0$, the percentage change of relative decrease in FS with $\alpha_{v}$ from 0.0 to 0.10 towards the direction of gravity is $44.4 \%$ and the 
percentage change of relative increase in $F S$ with $\alpha_{v}$ from 0.0 to 0.10 against the direction of gravity is $53.7 \%$.

\section{Study 6: Effect of avon FS for different $\gamma^{*}$}

In this study influence of unit weight of rock with varying vertical seismic coefficient on factor of safety has been presented.

Figure 8 presents the result for different values of unit weight of rock $\left(\gamma^{*}\right)$ as 2.0, 2.25, $2.5,2.75,3.0$ considering a specific set of influential parameters in their non-dimensional form as mentioned in Table 1.

From Fig. 8a, it is observed that the variation of unit weight of rock has no significant effect on FS. From Fig. 8a it is observed FS reduces with an increase in $\alpha_{v}$ against the direction of gravity and increases with $\alpha_{v}$ towards the direction of gravity. But the variation of $F S$ with $\alpha_{v}$ is almost insignificant. For $\gamma^{*}=2.0$, the percentage change of relative increase in $F S$ is $16.8 \%$ with increase in $\alpha_{v}$ towards the direction of gravity and that is $14 \%$ against the direction of gravity. As $\gamma^{*}$ increases, the variation of $F S$ with $\alpha_{v}$ increases in either direction of gravity. Variation of $F S$ with $\alpha_{v}$ is found to be maximum at higher value of $\gamma^{*}=3.0$. At $\gamma^{*}=3.0$, the percentage change of relative decrease in $F S$ with $\alpha_{v}$ from 0.0 to 0.1 against the direction of gravity is $21.3 \%$ whereas that towards the direction of gravity is $17.88 \%$.

From Fig. 8b Factor of safety decreases as $\alpha_{v}$ increases towards the direction of gravity whereas it increases with increase in $\alpha_{v}$ against the direction of gravity. Variation of FS with $\alpha_{v}$ is observed to be more for higher value of $\gamma^{*}$. At $\gamma^{*}=3.0$, the percentage change of relative decrease in $F S$ with $\alpha_{v}$ from 0.0 to 0.10 towards the direction of gravity is $43.2 \%$ and that against the direction of gravity is $52.4 \%$.

\section{Study 7: Effect of $a_{v}$ on FS for different $q^{*}$}

Study 7 presents the behaviour of rock slope in terms of factor of safety with the application of different amount of surcharge with varying vertical seismic coefficient.

Figure 9 presents the result for different magnitude of surcharge $\left(q^{*}\right)$ considering a specific set of influential parameters in their non-dimensional form as mentioned in Table 1.

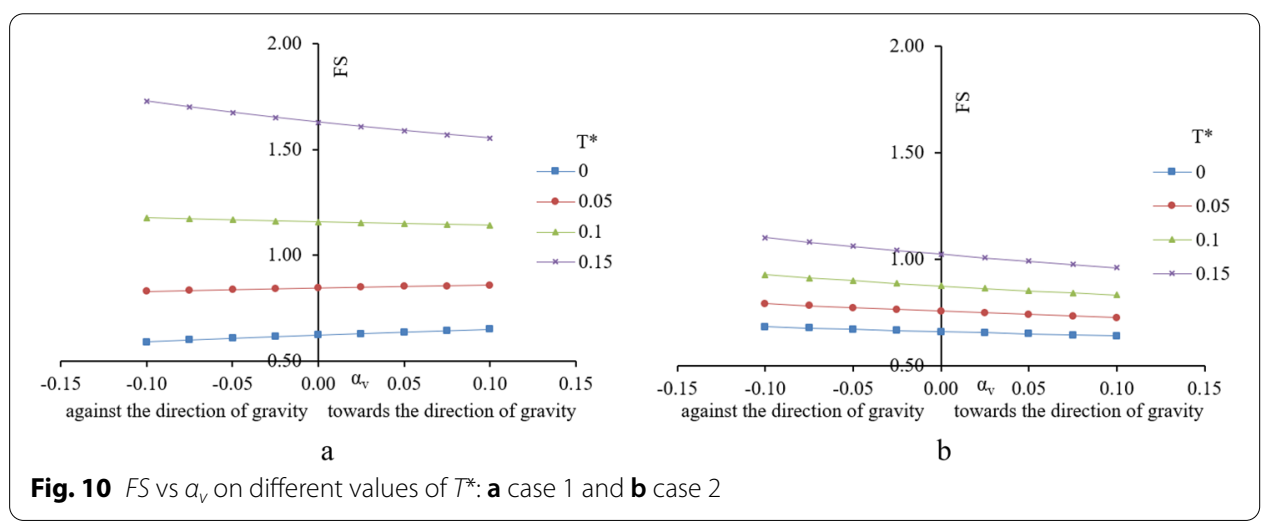


From Fig. 9a, it is observed that FS decreases with an increase in surcharge $q^{*}$ as surcharge directly adds weight to the sliding rock mass consequently increases the shear stress along the failure plane. Variation of $F S$ with $\alpha_{v}$ is almost linear. FS increases with increase in the value of $\alpha_{v}$ towards the direction of gravity whereas FS decreases with increase in the value of $\alpha_{v}$ against the direction of gravity. But the rate of increase of FS with $\alpha_{v}$ towards the direction of gravity is less than the rate of decrease of $F S$ with $\alpha_{v}$ against the direction of gravity. However, this variation of $F S$ with $\alpha_{v}$ is not so significant and maximum variation is observed at $\mathrm{q}^{*}=0.3$. At $\mathrm{q}^{*}=0.3$, the percentage change of relative decrease in $F S$ with $\alpha_{v}$ from 0 to 0.1 is only $1.89 \%$ against the direction of gravity and that towards the direction of gravity is $1.59 \%$.

From Fig. 9b, it is observed that for lower value of $q^{*}$, variation of $F S$ is more with $\alpha_{v}$ and for higher value of $q^{*}$, variation of $F S$ is less with $\alpha_{v}$ in both of the direction of gravity and observed maximum at $q^{*}=0.25$. Variation of $F S$ with $\alpha_{v}$ is almost linear. For $q^{*}$ greater than 0.5 , with the variation in vertical seismic coefficient, FS does not change significantly in both of the direction of gravity. FS reduces with increase in surcharge $\left(q^{*}\right)$. When $q^{*}$ varies from 0.0 to 0.5 , the rate of decrease of $F S$ is more than that when $q^{*}$ varies from 0.5 to 1.5 . At $q^{*}=0.25$, the percentage change of relative decrease in $F S$ with $\alpha_{\mathrm{v}}$ from 0.0 to 0.10 towards the direction of gravity is $66.8 \%$ and that against the direction of gravity is $82 \%$.

\section{Study 8: Effect of $\mathrm{a}_{\mathrm{v}}$ on FS for different $\mathrm{T}^{*}$}

Study 8 presents the influence of rock anchor stabilising force $\left(T^{*}\right)$ with varying vertical seismic coefficient on factor of safety of rock slope.

Figure 10 presents the results for different value of rock anchor stabilizing force $\left(T^{*}\right)$ as $0.0,0.05,0.1,0.15,0.20$ considering a specific set of influential parameters in their nondimensional form as mentioned in Table 1.

From Fig. 10, it is observed that FS increases with increase in rock anchor stabilising force significantly. From Fig. 10a, it is observed that when $T^{*}$ greater than 0.1, FS becomes more than unity at all the considered value of $\alpha_{v}$ hence slope becomes stable. For lower value of $T^{*}$ less than 0.1, FS increases with increase in the value of $\alpha_{v}$ towards the direction of gravity and decreases with increase in the value of $\alpha_{v}$ against the direction of gravity. But for higher value of $T^{*}, F S$ decreases with increase in $\alpha_{v}$ towards the direction of gravity and increases with increase in $\alpha_{v}$ against the direction of gravity

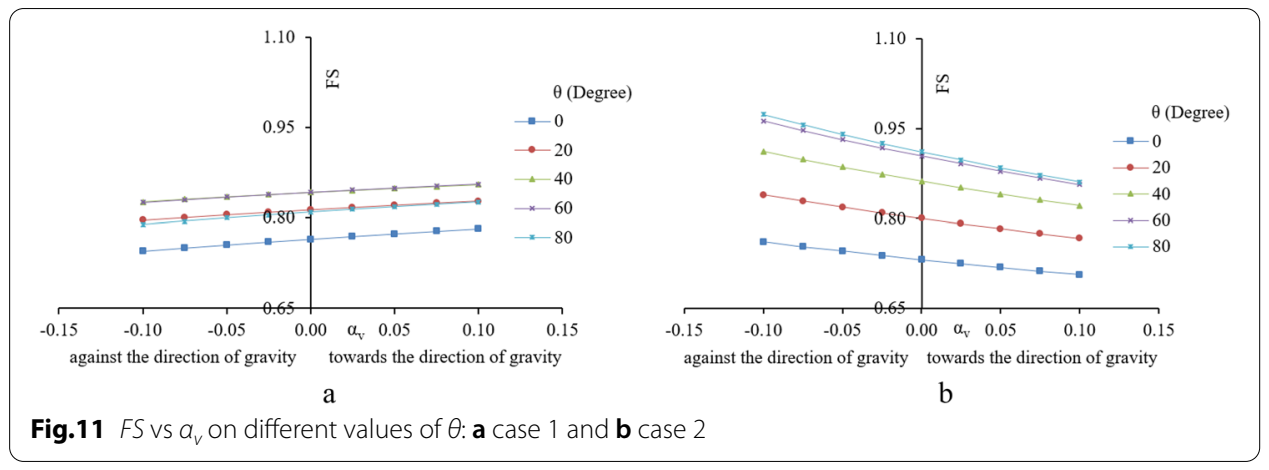


and the maximum variation of $F S$ is observed at $T^{*}=0.15$. At $T^{*}=0.15$, the percentage change of relative decrease in $F S$ with $\alpha_{v}$, from 0.0 to 0.1 towards the direction of gravity is $75.8 \%$ whereas that against the direction of gravity is $99.9 \%$.

From Fig. 10b, it is observed that FS decreases with the increase in $\alpha_{v}$ towards the direction of gravity and increases with the increase in $\alpha_{v}$ against the direction of gravity. But variation in FS with $\alpha_{v}$ for lower value of $T^{*}$ is less, more for higher value of $T^{*}$ and maximum at $T^{*}=0.15$. At $T^{*}=0.15$, the percentage change of relative increase in FS with $\alpha_{v}$ from 0.0 to 0.10 against the direction of gravity is $9.74 \%$ and the percentage change of relative decrease in $F S$ with $\alpha_{v}$ from 0.0 to 0.10 towards the direction of gravity is $7.58 \%$.

\section{Study 9: Effect of $a_{\mathrm{v}}$ on FS for different $\theta$}

Study 9 presents the influence of angle of inclination of the rock anchor stabilising force to the normal at the failure plane $(\theta)$ with varying vertical seismic coefficient $\left(\alpha_{v}\right)$ on factor of safety.

Figure 11 presents the results for different value of $\theta$ as $0^{\circ}, 20^{\circ}, 40^{\circ}, 60^{\circ}, 80^{\circ}$ considering a specific set of influential parameters in their non-dimensional form as mentioned in Table 1.

It is observed from Fig. 11a that the Factor of safety increases with increase in the value of $\theta$ from $0^{\circ}$ to $40^{\circ}$, then becomes nearly constant up to $60^{\circ}$ and then decreases when $\theta$ more than $60^{\circ}$. FS increases with increase in the value of $\alpha_{v}$ towards the direction of gravity and decreases with increases in the value of $\alpha_{v}$ against the direction of gravity. But rate of decrease in $F S$ with $\alpha_{v}$ against the direction of gravity is more than the rate of increase of $F S$ with $\alpha_{\nu}$ towards the direction of gravity. As $\theta$ increases from $0^{\circ}$ to $60^{\circ}$, variation of $F S$ with $\alpha_{v}$ becomes lesser, but it is found highest at $\theta=80^{\circ}$. At $\theta=80^{\circ}$, the percentage change of relative increase in $F S$ with $\alpha_{v}$ from 0.0 to 0.1 towards the direction of gravity is $1.69 \%$ and that against the direction of gravity is $2.05 \%$.

From Fig. 11b, it is observed that with increase in value of $\theta, F S$ increases. FS decreases with increase in $\alpha_{v}$ towards the direction of gravity and increases with increase in $\alpha_{v}$ against the direction of gravity. With variation of $\theta$ from $0^{\circ}$ to $40^{\circ}$ the rate of increase of $F S$ is more. Variation of $F S$ with $\alpha_{v}$ is observed to be maximum at $\theta=80^{\circ}$. At $\theta=80^{\circ}$, the percentage change of relative decrease in $F S$ with $\alpha_{v}$ from 0.0

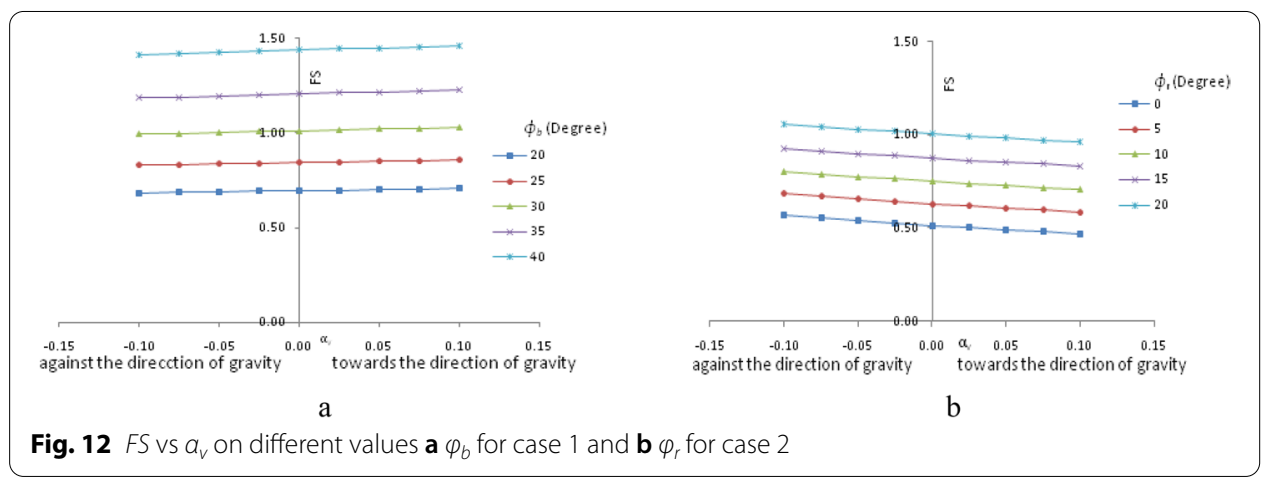




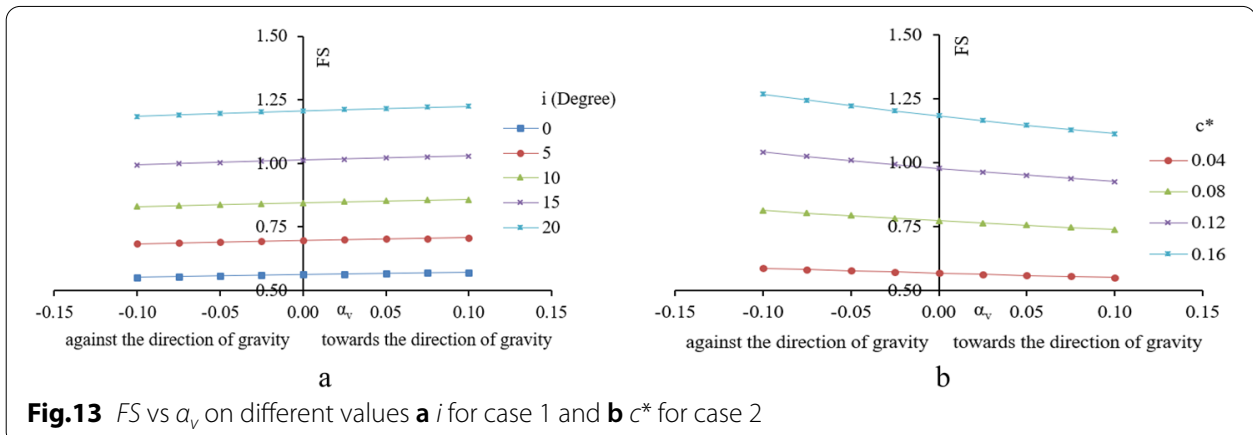

to 0.10 towards the direction of gravity is $50.3 \%$ and that against the direction of gravity is $62.2 \%$.

\section{Study 10: Effect of $\alpha_{v}$ on FS for different $\varphi_{b}$ and $\varphi_{r}$}

In this study, the stability condition of rock slope for different basic frictional angle and residual frictional angle with varying vertical seismic coefficient have been studied.

Figure 12 presents variation of factor of safety $(F S)$ of rock slope with vertical seismic coefficient $\left(\alpha_{v}\right)$ for different values of (a) basic friction angle $\left(\phi_{b}\right)$ for case 1 and (b) residual friction angle $\left(\phi_{r}\right)$ for case 2 , considering a specific set of influential parameters in their non-dimensional form as mentioned in Table 1.

From Fig. 12a, it is observed that FS increases significantly with increase in the angle of friction angle. For $\phi_{b}$ greater than $30^{\circ}, F S$ becomes more than unity. Hence slope becomes stable. FS increases with increase in the value of $\alpha_{v}$ towards the direction of gravity and decreases with increase in the value of $\alpha_{v}$ against the direction of gravity. This variation of $F S$ with $\alpha_{v}$ is more for higher value of $\phi_{b}$. At $\phi_{b}=80^{\circ}$, the percentage change of relative increase in $F S$ with $\alpha_{v}$ from 0.0 to 0.1 towards the direction of gravity is $2.19 \%$ and that against the direction of gravity is $2.64 \%$.

From Fig. 12b, it is observed that FS increases with an increase in the value of $\phi_{r}$. Rate of increase of $F S$ with $\phi_{r}$ remains nearly constant. It is because of the linear behaviour of Patton's model of shear strength for high normal stress. As $\phi_{r}$ increases, the rate of variation of $F S$ decreases but that is not very significant. $F S$ decreases with increase in $\alpha_{v}$ towards the direction of gravity and increases with increase in $\alpha_{v}$ against the direction of gravity almost linearly. Variation of $F S$ with $\alpha_{v}$ is observed to be maximum at $\phi_{r}=5^{\circ}$. At $\phi_{r}=5^{\circ}$, the percentage change of relative decrease in $F S$ with $\alpha_{v}$ from 0.0 to 0.10 towards the direction of gravity is $44.7 \%$ and the percentage change of relative increase in $F S$ with $\alpha_{v}$ from 0.0 to 0.10 against the direction of gravity is $53.6 \%$.

\section{Study 11: Effect of $a_{v}$ on FS for different $i$ and $c^{*}$}

In this Study, the influence of inclination angle of asperities along the joint surface and cohesion with varying vertical seismic coefficient on rock slope stability have been observed. 
Figure 13 presents the results for different value of (a) inclination angle $(i)$ as $0^{\circ}, 5^{\circ}, 10^{\circ}$, $15^{\circ}, 20^{\circ}$, and (b) cohesion $\left(c^{*}\right)$ as $0.0,0.04,0.08,0.12,0.16$ considering a specific set of influential parameters in their non-dimensional form as mentioned in Table 1.

From Fig. 13a, it is observed that FS increases significantly as angle of inclination of jointed rock increases. FS increases with increase in the value of $\alpha_{v}$ towards the direction of gravity and decreases with increase in the value of $\alpha_{v}$ against the direction of gravity. Variation of $F S$ with $\alpha_{v}$ is linear. Rate of decrease of $F S$ with $\alpha_{v}$ against the direction of gravity is more than the rate of increase of $F S$ with $\alpha_{v}$ towards the direction of gravity. As the inclination angle of jointed rock increases, variation of $F S$ with $\alpha_{v}$ increases in both the direction of gravity. At $i=20^{\circ}$, the percentage change of relative increase in $F S$ with $\alpha_{v}$ from 0.0 to 0.1 towards the direction of gravity is $1.83 \%$ and that against the direction of gravity is $2.21 \%$, thus the variation is not so significant.

From Fig. 13b, it is observed that FS increases with increase in cohesion. FS decreases with increase in $\alpha_{v}$ towards the direction of gravity and increases with increase in $\alpha_{v}$ against the direction of gravity almost linearly. As cohesion increases, rate of variation of $F S$ with $\alpha_{v}$ increases and observed to be maximum at $c^{*}=0.16$. At $c^{*}=0.16$, the percentage change of relative decrease in FS with $\alpha_{v}$ from 0.0 to 0.10 towards the direction of gravity is $69.8 \%$ and that against the direction of gravity is $84.6 \%$.

\section{Conclusion}

This paper presents the results of a number of pseudo-static seismic stability analyses of an idealised rock slope, considering a planar failure mechanism and adopting the Limit Equilibrium Method (LEM) and the Patton's shear strength criterion. In the analyses, some actually occurring conditions were considered, i.e. the presence of a tension crack at the slope back, hydrostatic pressures acting along both the basal failure plane and the tension crack, surcharge and stabilising rock bolt. Also, an expression of normal stresses as limiting criterion has been derived in order to compare the field normal stresses along the failure surface. Based on the limiting criterion, expressions for factor of safety for low and high normal stresses along failure plane are developed. The pseudo-static seismic stability analyses were carried out in order to evaluate the influence of the vertical seismic acceleration on the factor of safety of the slope, for various reference configurations.

Based on the studies undertaken in this paper, the following concluding remarks can be made:

1. For high normal stress along failure plane, it is observed that the factor of safety decreases with increase in the value of vertical seismic coefficient towards the direction of gravity and increases linearly with increases in the value of vertical seismic coefficient against the direction of gravity. In the case of high normal stress along the failure plane, driving mechanism is gravitational body force, since the vertical seismic force affects the normal stress, and hence the shear strength along the failure slope. when the vertical seismic acceleration increases the slope becomes potentially unstable. Opposite trend of factor of safety with vertical seismic coefficient have been found for low normal stress. It is due to occurrence of pure sliding phenomena 
along the discontinuities of rock mass along the failure plane at low stress. Vertical seismic acceleration has to be considered in the analysis especially when the horizontal seismic acceleration is high. Effect of vertical seismic coefficient against the direction of gravity has predominant effect on factor of safety of rock slope as the rate of increase/decrease of factor of safety with vertical seismic coefficient is more against the direction of gravity. Hence in determining the critical factor of safety, the vertical seismic coefficient against the direction of gravity should be considered.

2. Factor of safety of rock slope reduces with increase in horizontal seismic coefficients. Reduction in factor of safety appears to be in proportional to the increase in horizontal seismic coefficient.

3. Factor of safety of rock slope increases as the depth of tension crack increases. It is due to geometrical changes in the sliding rock mass over failure plane. Results show that the presence of water in tension crack can reduce the factor of safety significantly. In practical situation, measurement of depth of tension crack and water depth present in it may be difficult. Uncertainty of depth of tension crack and water present in it may have significant effect on stability of rock slope. Probabilistic analysis might be the better way to explore the effect of depth of tension crack and presence of water in tension crack on the stability of rock slope.

4. Unit weight of rock does not have significant effect on factor of safety of rock slope. But over the long span of life, to quantify the effect of unit weight, sensitivity analysis using probabilistic techniques would be the better approach. In the rock slope analysis, strength primarily depends on the cohesion and basic and residual frictional angles and increase in factor of safety appears to be proportional to increase in cohesion and friction angle.

5. Presence of surcharge reduces factor of safety significantly as surcharge directly adds weight to the sliding rock mass consequently increases the shear stress along the failure plane. Result shows that rate of decrement in factor of safety is higher for low value of surcharge and lesser for higher value of surcharge with the increase in seismic forces. Hence limiting the surcharge over rock slope can improve the safety of slope significantly.

6. Rock anchor stabilising force with angle of inclination of the rock anchor stabilising force to the normal $(\theta)$ to failure plane has important role in making the slope stable. Factor of safety increases with increase in rock anchor stabilising force but it increases with $\theta$ up to approximately $60^{\circ}$ then it decreases beyond $60^{\circ}$.

7. Factor of safety of rock slope increases with residual friction angle and cohesion. Rate of increase of factor of safety of rock slope increases with increase in residual friction angle but it remains constant with cohesion.

8. In case of factor of safety calculation for low normal stress, FS increases with basic friction angle and angle of inclination of asperities along the basal discontinuity with horizontal. Undulations along the discontinuities has significant influence on shear behaviour.

For the stability analysis of rock slope, the Psuedo-static analysis has been adopted which does not account for the cyclic nature of loading. The effect of cyclic loading will be considered in future studies. 
Authors' contributions

Consent to submit has been received explicitly from all co-authors. Authors whose names appear on the submission have contributed significantly to the work submitted.

\section{Funding}

No funding was received for this work.

Availability of data and materials

Some or all data, models, or code generated or used during the study are available from the corresponding author by request.

\section{Competing interests}

No potential conflict of interest in the subject matter discussed in this manuscript.

Received: 28 October 2020 Accepted: 15 December 2020

Published online: 06 March 2021

\section{References}

1. Ahmadi M, Eslami M (2011) A new approach to plane failure of rock slope stability based on water flow velocity in discontinuities for the Latian dam reservoir landslide. J Mt Sci 8(2):124-130. https://doi.org/10.1007/s1162 9-011-2088-5

2. Das S, Maheshwari BK (2019) Effect of Vertical seismic coefficient in Slope Stability Analysis. In: 7th Indian Young Geotechnical Engineers Conference (7IYGEC 2019). NIT Silchar, Assam

3. Goodman RE, Kieffer DS (2000) Behavior of Rock in Slopes. J Geotech Geoenvironmental Eng 126(8):675-684. https ://doi.org/10.1061/(ASCE)1090-0241(2000)126:8(675)

4. Hocking $G$ (1976) A method for distinguishing between single and double plane sliding oftetrahedral wedges. Int $J$ Rock Mech Min Sci 13(7):225-226

5. Hoek E (2007) Practical rock engineering. https://www.rocscience.com/assets/resources/learning/hoek/PracticalRock-Engineering-Full-Text.pdf. Accessed 2 March 2020

6. Hoek E, Bray JW (1981) Rock slope engineering, Revised. Institute of Mining and Metallurgy, London

7. Hossain MM (2011) Stability analysis of anchored rock slopes against plane failure subjected to surcharge and seismic loads. Edith Cowan University, Australia

8. Hossain MM, Shukla S (2010) Effect of Vertical Seismic Coefficient on the Stability of Rock Slopes Against Plane Failure. In: 6th Australasian Congress on Applied Mechanics. Engineers Australia, Perth, W.A., pp 648-656. https:// ro.ecu.edu.au/ecuworks/6387/

9. Ingles J, Darrozes J, Soula J-C (2006) Effects of the vertical component of ground shaking on earthquake-induced landslide displacements using generalized Newmark analysis. Eng Geol 86(2-3):134-147. https://doi.org/10.1016/j. enggeo.2006.02.018

10. IS 1893 (2016) Indian standards criteria for earthquake resistant design of structures, Part 1. https://www.slideshare .net/gaya30/is-1893-part-12016

11. Karaman K, Ercikdi B, Kesimal A (2013) The assessment of slope stability and rock excavatability in a limestone quarry. Earth Sci Res J 17:169-181

12. Keefer DK (2000) Statistical analysis of an earthquake-induced landslide distribution — the 1989 Loma Prieta. California event. Eng Geol 58(3):231-249. https://doi.org/10.1016/S0013-7952(00)00037-5

13. Kliche C (1999) Rock slope stability. Society for Mining, Metallurgy, and Exploration Inc (SME), USA

14. Kovári K, Fritz P (1984) Recent developments in the analysis and monitoring of rock slopes. In: IVth International symposium on landslides, Toronto, Canada. Canadian geotechnical Society, Toronto, Canada, pp 1-16

15. Kramer SL (1996) Geotechnical earthquake engineering. Prentice Hall, Upper Saddle River

16. Lee C-Y, Wang I-T (2011) Analysis of highway slope failure by an application of the stereographic projection. World Acad Sci Eng Technol 75:515-523

17. Ling HI, Cheng AH-D (1997) Rock sliding induced by seismic force. Int J Rock Mech Min Sci 34(6):1021-1029. https:// doi.org/10.1016/S1365-1609(97)80011-1

18. Low BK (2007) Reliability analysis of rock slopes involving correlated nonnormals. Int J Rock Mech Min Sci 44(6):922935. https://doi.org/10.1016/j.jirmms.2007.02.008

19. Patton FD (1966) Multiple modes of shear failure in rock. In: Proceedings of the 1st ISRM Congress, International society for rock mechanics, Lisbon, Portugal, September-October 1966, Vol. 1, pp. 509-513. https://onepetro.org/ isrmcongress/proceedings-abstract/CONGRESS66/All-CONGRESS66/ISRM-1CONGRESS-1966-087/166024

20. Price DG (2009) Engineering Geology - Principles and Practice. Springer-Verlag, Berlin Heidelberg

21. Ramamurthy $T$ (2014) Engineering in Rocks for Slopes, Foundations and Tunnels, Third. Prentice Hall India Learning Private Limited

22. Sarma SK, Scorer M (2009) The effect of vertical acceleration on seismic slope stability. In: Proceedings of the international conference on performance based design in earthquake geotechnical engineering. Tokyo, Japan. https:// doi.org/10.13140/2.1.2814.3045

23. Sharma S, Raghuvanshi T, Sahai A (1999) An engineering geological appraisal of the Lakhwar Dam, Garhwal Himalaya India. Eng Geol 53(3):381-398. https://doi.org/10.1016/S0013-7952(99)00038-1

24. Sharma S, Raghuvanshi TK, Anbalagan R (1995) Plane failure analysis of rock slopes. Geotech Geol Eng 13(2):105111. https://doi.org/10.1007/BF00421876 
25. Shukla SK, Khandelwal S, Verma VN, Sivakugan N (2009) Effect of surcharge on the stability of anchored rock slope with water filled tension crack under seismic loading condition. Geotech Geol Eng 27(4):529-538. https://doi. org/10.1007/s10706-009-9254-3

26. Stead D, Eberhardt E, Coggan JS (2006) Developments in the characterization of complex rock slope deformation and failure using numerical modelling techniques. Eng Geol 83(1):217-235. https://doi.org/10.1016/j.engge 0.2005 .06 .033

27. Tang H, Yong R, Ez Eldin MAM (2017) Stability analysis of stratified rock slopes with spatially variable strength parameters: the case of Qianjiangping landslide. Bull Eng Geol Environ 76(3):839-853. https://doi.org/10.1007/s1006 4-016-0876-4

28. Yoon WS, Jeong UJ, Kim JH (2002) Kinematic analysis for sliding failure of multi-faced rock slopes. Eng Geol 67(1):51-61. https://doi.org/10.1016/S0013-7952(02)00144-8

\section{Publisher's Note}

Springer Nature remains neutral with regard to jurisdictional claims in published maps and institutional affiliations.

\section{Submit your manuscript to a SpringerOpen ${ }^{\circ}$} journal and benefit from:

- Convenient online submission

- Rigorous peer review

- Open access: articles freely available online

- High visibility within the field

Retaining the copyright to your article

Submit your next manuscript at $\gg$ springeropen.com 